\title{
SUPERNUMERARY LEFT KIDNEY PRESENTING AS ADRENAL NODULE
}

\section{S.Pathmanathan, N.Illukumbura, S.Sriram}

District General Hospital Trincomalee.

A 49-year-old woman was evaluated after an adrenal nodule is discovered on a CT scan (Abdomen) obtained because of uncontrolled hypertension. She also complained of irregular periods and hirsutism. There was no weight gain over the past year. She was a known hypothyroid patient on thyroxine 75ug daily. She had no history of diabetes mellitus, palpitations, headaches, or sweating and no pertinent family history. She was on prazocin $1 \mathrm{mg}$ tds, amlodipine 10 mg mane, carvedilol $6.25 \mathrm{mg}$ bd, thyroxine $75 \mathrm{ug}$ mane, clopidogrel $75 \mathrm{mg}$ nocte and atorvastatin $20 \mathrm{mg}$ nocte. On physical examination, blood pressure was $148 / 96 \mathrm{mmHg}$, pulse rate is $88 / \mathrm{min}$, and $\mathrm{BMI}$ is 34 $\mathrm{KgM}^{2}$. General physical examination findings were normal.

Laboratory studies: Electrolytes Na-144 meq/L, K$3.9 \mathrm{meq} / \mathrm{L}$, Aldosterone to renin activity ratio 1.1 (normal <30), 9 am Cortisol $359 \mathrm{nmol} / \mathrm{L}$ (138-690 $\mathrm{nmol} / \mathrm{L})$, Low dose dexamethasone suppression test $<22 \mathrm{nmol} / \mathrm{L}, 24$ hour urinary VMA: 7.3mg/24 hr(1-11 $\mathrm{mg} / 24 \mathrm{hr}$ ). Her testosterone level was normal.

She underwent a comprehensive Contrast Enhanced CT Adrenal which revealed hypoplastic, fused supernumerary left kidney cranial to normal left kidney.

Supernumerary kidneys are a rare congenital anomaly of the urogenital system, where there are one or two accessory kidneys. Less than 100 cases are documented. Patients may be asymptomatic. If present, symptoms range from fever, pain to abdominal mass. Most of the kidneys are on the left and is smaller in size with reduced excretion as in our patient.

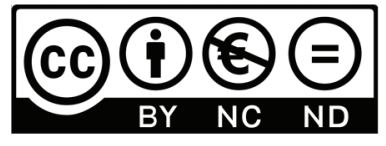

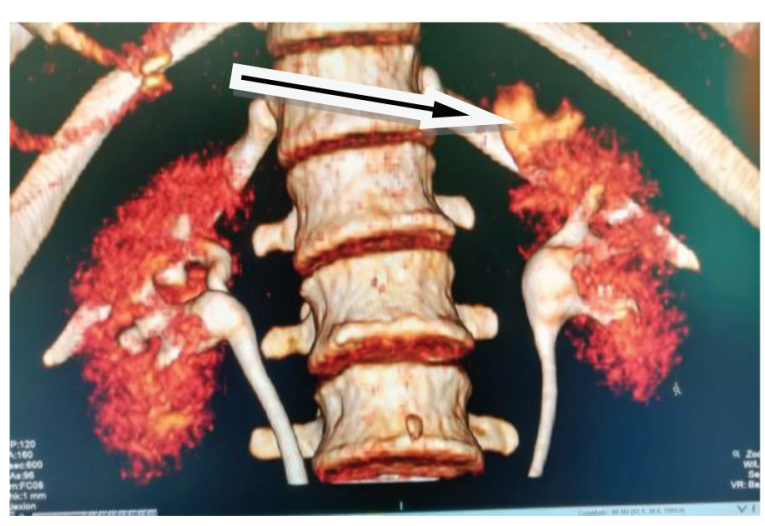

Fig 1: Arrow points towards the structure seen cranial to L/kidney - supernumerary kidney.

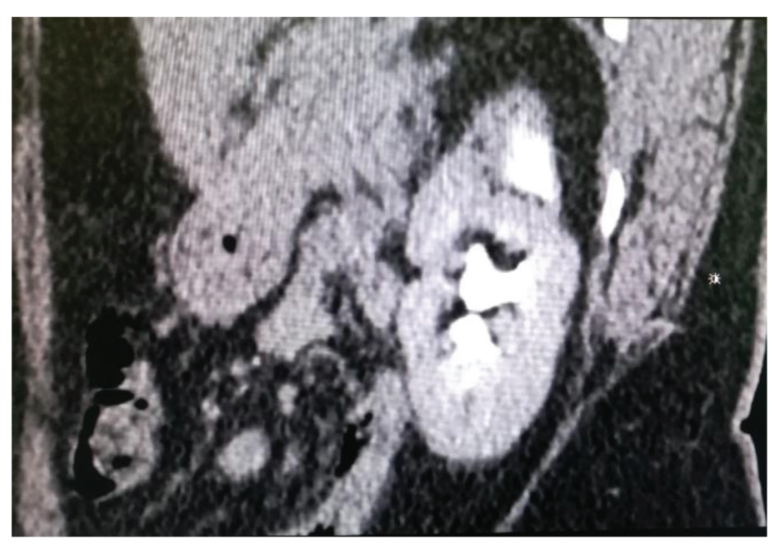

Fig 2: Arrow points towards the structure seen cranial to L/kidney showing excretion of contrast during delayed phase consistent with a renal tissue indicating supernumerary kidney.

Her hypertension was diagnosed as essential hypertension and currently under control on 3 antihypertensives. 
The Internet Journal of Radiology. 2013; 15

(1):1-5.

\section{REFERENCES:}

1. Mitra AR, Janjua. Diabetes in South Asians: Etiology and the Complexities of Care. UBCMJ 2010; 2 (1): 20-3.

2. Suresh N, Navin Gnanasekaran N, Bhawna Dev. Fused supernumerary kidney Radiology Case Reports. 2011; 6(4): 552.

3. N'Guessan G, Stephens FD Supernumerary kidney Journal of Urology.1983 Oct; 130(4): 649-53.

4. Adekanmi A, Atalabi O, Ukachukwu I. Supernumerary Kidney (Triple Kidney) With Horseshoe Component: A Case Report. 